the first twelve days of incubation up to the time of the appearance of creatin. That the cholin of the lecithin of the yolk is the precursor is rendered probable by the evidence adduced by Reisser and by Baumann Hines and Marker that creatin is formed from cholin.

That free methyl-guanidin is a normal constituent of muscle has been shown by the work of various investigators, and these results have been confirmed recently by Henderson. It is a normal constituent of the urine, even of such animals as the horse, which lives upon a creatin-free diet.

Guanidin and methyl-guanidin have marked physiological actions. They stimulate the efferent neurons of the spinal cord, causing tremors, jerkings, and extensor tonus. In large doses applied to the spinal cord, they paralyse. On the nerve-endings in muscle they have first a stimulating effect, so that the electrical excitability is increased, but later and in large doses they have a curare-like action. The symptoms are similar to those following ablation of the parathyreoids and to those of idiopathic tetany in children. In the blood and in the urine of parathvreoid ectomised dogs and in the urine of children with tetany, Burns and Sharpe demonstrated an enormous increase in the amount of guanidin present, an increase to which Koch had previously directed attention.

The conclusion seems to be that, under normal conditions, free methyl-guanidin maintains a tonic action on the efferent neurons and so on the muscles, and that the amount of guanidin is controlled by the parathyreoids.

The few observations so far made point to the excretion unchanged of only a part of injected guanidin. A possible explanation of this seems to be that part is linked with acetic acid and so converted to creatin and then rendered inert.

Previous work on the formation of creatin from glycocyamin, guanidin acetic acid, renders this prob. able. Recently in my laboratory Wishart has found a distinct increase in the creatin content of the muscles after the injection of guanidin sulphate, thus proving the conversion.

The nature of the combination of creatin in muscle is not yet known. Folin maintains that creatin is an integral part of the muscle substance, and that it is liberated as muscle dies and disintegrates. Evidence of this is lacking, and some recent experiments by Wishart show that in muscle frozen during life and exfracted near the freezing-point the creatin content is the same as in muscle treated in the usual wav. Folin's own work on the concentration of creatin in muscle does not seem to support his theory.

In the light of these results and of this view of the mode of formation of creatin from guanidin, what is the significance of the creatin which appears in the urine? This problem may best be investigated in animals in which the question of the relationship of creatin to creatinin need not be considered. Meissner in 1868 maintained that this is the case in birds, and his conclusion I verified in rgro. It has since been further substantiated by the work of Thompson. In birds during fasting the excretion of creatin is increased, just as in mammals the excretion of the combined creatin and creatinin is generally increased. Myers and Fine claim that the creatin excreted is derived from the creatin present in muscle at the beginning of the fast, while Stanley Benedict and Osterberg maintain that there is a constant fresh formation of creatin. The experimental basis of the latter conclusion seems to be unsubstantial, since they administered protein containing arginin and therefore guanidin, from which the creatin might have been formed.

In 1910 I maintained that, from the amount of NO. $26 \mathrm{I}_{2}$, VOL. $\left.\mathrm{IO}_{4}\right]$ creatin excreted by the bird during a fast, the amount of muscle disintegrated might be calculated. Whether the liberated creatin is simply excreted, or whether its resynthesis into muscles is prevented, the amount in the urine indicates the breakdown and non-regeneration of muscle, i.e. the actual disintegration. Hence a study of the relationship of the creatin nitrogen to the total nitrogen excreted enables a conclusion to be drawn as to whether the loss is falling chiefly upon muscle or upon other organs of the body. A study of the metabolism of the bird in fasting shows that such conclusions may be drawn, and, accepting Folin's most recent view of the significance of urinary creatin and creatinin, the excretion of the nitrogen in these substances, taken along with the total excretion of nitrogen, affords a means of elucidating further the progress of protein metabolism in fasting.

The work of Cathcart and others seems to show that creatin, in the presence of carbohydrates, may be resynthesised into the muscle substance. This in no way invalidates the view that it is formed to detoxicate guanidin. Lecithin, which is undoubtedly used in the construction of the tissues, plays a like part in detoxicating cholin.

As regards the relationship of creatin to creatinin, in spite of the very considerable literature which has appeared upon the subject, our knowledge has advanced little since the time of Meissner. The mass of evidence seems to favour the view that the creatinin daily excreted is derived from the creatin of muscle, but that the power of conversion is very limited, and that it varies in different individuals and in different species of animal.

The considerations here adduced seem to point to the conclusions :- ( $\mathrm{r}$ ) That creatin is formed from excess guanidin or methyl-guanidin in order to limit the toxic action of these; (2) that it is to a limited extent stored in muscle, any excess being excreted in the urinc. either unchanged as in the bird, or in the form of creatinin in the mammal; (3) that during fasting and in the absence of carbohydrates it is liberated as the muscle disintegrates; and (4) that it may be re. combined into the muscle molecule if the supply of carbohydrates is adequate.

\section{RADIOTELEGRAPHY DURING THE SOLAR ECLIPSE OF MAY 29.}

$\mathrm{N}$ connection with the solar eclipse of May 29 the committee arranged for the carrying out of experiments on the effect of the eclipse on signals transmitted across the central line. The British Admiralty stations at Ascension and the Azores transmitted continuously during the transit of the umbra across the Atlantic Ocean. Observing stations north of the equator were for the most part asked to listen to Ascension for at least an hour round about the time when the umbra passed between themselves and Ascension; observers south of the equator were asked for the most part to listen to the Azores. Certain selected stations north of the equator were also asked to listen to the Azores, so as to afford check observations upon the variations which might be observed in signals passing across the central line of the eclipse, and, similarly, selected stations south of the central line were aslied to listen to Ascension. The American station at Sayville also transmitted a programme during a portion of the period of the eclipse, and arrangements were made for special experiments between Darien and the Falklands, and between an Egyptian station and a South African station.

1 Report of a Committee of the Britisl Association presented to Section A at the Bournemouth meeting, September rgrg. 
The main portion of the experiment hinged upon Ascension. The umbral cone passed from west to east, and was expected to affect in succession the strength in which signals were received at such stations as Demerara, Jamaica, the stations on the coast of the United States and Canada, stations in Ireland, England, France, Italy, the Mediterranean, and Egypt.

The shadow of the moon struck the earth first at dawn on the coast of South America and swept across the continent in the course of half an hour, at first with enormous velocity, but losing speed as the Atlantic Ocean was approached. About the middie of the Atlantic Ocean and near the equator the speed of the shadow was about one-third of a mile per second. On crossing the African continent from the Gulf of Guinea to the Mozambique Channel the speed gradually increased, and the eclipse finished at sunset near Madagascar. The effects of the moving shadow were investigated under three heads:--

(1) Strays.

(2) Signals not crossing the denser parts of the shadow.

(3) Signals crossing through or near the umbra.

\section{Strays.}

These were bad on the day of the eclipse and on the preceding day in Europe. North America, and temperate latitudes on the Atlantic Ocean. Thry were very few in Central and South America and in the central equatorial Atlantic. In Central America the conditions were exceptional meteorologically, the dav having less rain than nearlv every dav of the preceding three weeks. The preliminary survey of the results recorded throughout the part of the globe reaching from Constantinople to $\mathrm{Rio}$ de Janciro suggests that there was no outstanding occurrence in regard to frequency or intensity of stravs that could be directly ascribed to the passage of the shadow.

Signals not Traversing the Dense Shadow.

Many observations were made in northern Europe and America on the signals from the Azores, which were arc-signals of 4700 metres wave-length. The observing points extended from Berlin through Holland, France, Italy, Spain, and Great Britain to stations near the Atlantic coast of the United States. There were no unusual variations in the strensth of the signals from the Azores.

Another class of experiment comes under this head. ing. It was suggested by the effect sometimes observed at sunset or sunrisc, in which the twilight band when on one side of a transmitting station appears to strengthen as if by reflection the waves received at a station on the other side of the transmitting station. In order to test whether such reflections occurred Aurings an eclinse certain stations on the south of the central line of the eclinse were asked to listen to Ascension, which was also south of the central line. The stations at Durban and Port Nolloth (South. West Africa) found no trace of the effect, and, in fact. the former concluded that the signals from Ascension were rather worse after the eclinse began. An analogous experiment on the northern side was carried nut by one of the Malta stations and also at Rosvth, listening to Cairo, with similar conclusions.

\section{Effect of Signals Passing across the Central Line.}

Arrangements were made for the transmission of signals from the Darien station of the Panama Canal zone, and several stations in South America attempted to recrive the signals. The reoort from the Falliland Islands has not vet come to hand, and the other stations in South America did not succeed in picking No. 26 I2. VOL. IO4] up the signals. The only observation made on the earlier stages of the eclipse are those of Demerara listening to Ascension. Fluctuations in signal strength are reported, but no steady increase or de. crease in strength. Ships at sea within the penumbra report a strengthening of all signals during the eclipse. The most striking results were obtained at some of the stations in France, Malta, and Teneriffe. At Meudon and at Rousillon the signals from Ascension were received practically only while the eclipse was in progress. Both Malta and Teneriffe found that the eclipse produced a great improvement in the strength of signals. On the other hand, Durban was unable to pick up Cairo, though this is usually possible, but Aden was picked un with sreater intensity than normal. On the whole, the records show that the improvement in signal strength reached its highest value long hefore the umbra intervened between the stations, and this value persisted after the umbra had passed; that is to say, if ionising processes are the cause of the change in the strength of signals, the results indicate that the processes are practically fully accomplished in a given region of the air hefore the arrival of the umbra at that place, so that there appears to be nothing left for the umbra to do in the few minutes of complete shadow it brings.

The thanks of the committee are due especially to the Admiralty for arranging that their stations at Ascension and the Azores should transmit the neces. sary signals, and alsn to the American Government for making similar arrangements regarding Savville and Darien. Thanks are due also to the American, French. and Italian Governments, the Admiralty, the War Office, the Air Ministry, and Marconi's Wire less Telegraoh Co., I.td.. for undertaking observations and recording the variations in signal strength.

\section{UNIVERSITY AND EDUCATIONAL INTELLIGENCE.}

CAMBridiz.- The council of the Senate reports that, after consultation with Sir WV. J. Pope, it is considered desirable to establish a professorship of physical chemistry, the stipend of rool. per annum to be furnished out of the benefaction of the British Oil Companies.

The General Board of Studies has recommended the appointment of Mr. A. Amos, of Downing College, as Iniversity lecturer in ayriculture. This appoint. ment is proposed in view of the new scheme of study in agriculture, extending nver three years, and the larse increase of students in the department of agriculture.

GLasgow.--President P'oincaré was installed as Rector of the University on November I4, and delivered his rectorial address in English to an assembly of four thousand students and other members and friends of the University in St. Andrews Hall. The proceedings were conducted in admirat)le order, the students recognising that M. Poincare was not on? their Rector, but also the honoured chief of an Allied State visiting this country as his Majesty's guesr. The Vice-Chancellor, Sir Donald MacAlister, K.C.B. conferred on him the desree of LI..D. honoris causa before the installation. The Vice-Chancellor wore the Cross of Commander of the I-gion of Fonour, with which the President had privately invested him before the public ceremonv.

At a meeting of the Iniversity Court held afterwards, the Rector in the chair, a number of imnortant gifts to the University were announced. Among them were cointributions amounting to about $20,000 l$. for the erection of a memorial chapel in commemoration 